\title{
Intraosseous lipoma of the calcaneum
}

\author{
Khujat $\mathbf{R}^{1}$, Khaladkar S.M ${ }^{2}$, Kharat A ${ }^{3}$, Raj $\mathbf{R}^{4}$, Doshi F ${ }^{5}$, Gandage S.G ${ }^{6}$ \\ ${ }^{1}$ Dr. Rohan Khujat, Post Graduate Student, ${ }^{2}$ Dr. Sanjay M. Khaladkar, Professor, ${ }^{3}$ Dr. Amit Kharat, Professor, \\ ${ }^{4}$ Dr. Raunak Raj, Post Graduate Student, ${ }^{5}$ Dr. Foram Doshi, Post Graduate Student, ${ }^{6}$ Dr. S.G Gandage, Professor and \\ HOD; all authors are affiliated with Department of Radiology, Dr. D. Y. Patil Medical College and Research Centre, \\ Pune, Maharashtra, India.
}

Address for Correspondence: Dr. Rohan Khujat, Department of Radiology, Dr. D. Y. Patil Medical College and Research Centre, Pimpri, Pune, Maharashtra, India. E-mail: rohan_khujat@yahoo.com

\begin{abstract}
Calcaneal Intraosseous lipoma is a very rare lesion usually benign tumor, which constitutes not more than $2 \%$ of bone tumors. On plain radiographs, an intraosseous lipoma is usually seen as benign-appearing osteolytic bone lesion with well-defined margins and calcified/ossified dense matrix. Plain radiographs alone cannot establish the diagnosis of intraosseous lipoma as it imitates several other benign and malignant bone lesions. Intraosseous lipoma contains calcified necrotic fat with mature adipose tissue and characteristically induces expansion/remodeling of the affected bone.
\end{abstract}

Keyword: Intraosseous Lipoma (IL), Calcaneum, Stages of Intraosseous Lipoma.

\section{Introduction}

Intraosseous lipoma is most common lipogenous lesion of bone and found most frequently in the calcaneum, in $10-15 \%$ of cases $[1,2]$. These are composed of mature adipose tissue devoid of hematopoietic elements with variable amount of fibrous and vascular tissue, showing areas of fat necrosis and calcification [2]. The radiologic differential diagnosis are bone infarct, fibrous dysplasia, enchondroma, chondrosarcoma, osteoblastoma and simple bone cyst $[2,3]$.
It presents in 5 to 85 years with peak incidence in $4^{\text {th }}-5^{\text {th }}$ decade. They can occur anywhere in skeleton with predominance in lower limbs. In long bones, they commonly occur in metaphysis. Lower limb involvement is seen in $71 \%$ cases (Calcaneum $-32 \%$, femur $20 \%$, Tibia $13 \%$, Fibula $6 \%$ ), upper limb in $7 \%$, skull and mandible in $7 \%$, spine and pelvis in $12 \%$, ribs in $2.5 \%$ [4].

\section{Case Summary}

A 35 year old male patient came with complaint of pain at left ankle joint since 1 month. No history of restriction of movements, trauma or any surgery in past. Xray Lateral of left ankle showed a well circumscribed osteolytic lesion in body of calcaneus with no calification within it or periosteal reaction (Figure 1).

Plain CT Scan of Calcaneum revealed a well defined expansile hypodense fat density lesion (CT Value -60 to -100 HU) measuring approx. $2.4(\mathrm{AP}) \times 2.5(\mathrm{~T}) \times 2.1(\mathrm{CC}) \mathrm{cm}$ was noted at the body of calcaneum without any soft tissue component with thin sclerotic rim.

No calcification was noted in its central portion. (Figure 2 A-C) MRI of Calcaneum showed a well defined lesion measuring $2.5 \times 2.6 \times 2.1 \mathrm{~cm}$ in calcaneal bone appearing hyperintense on T1WI and T2WI (Figure $3 \mathrm{~A}-\mathrm{C}$ ) with fat suppression on STIR and PDFS (Figure 4). No marrow edema noted. No breaks in bony cortices are noted. Surrounding muscles and tendons appear normal. Diagnosis of intraosseous lipoma (Milgram Stage I) was made.

Manuscript received $25^{\text {th }}$ September 2016

Reviewed: $10^{\text {th }}$ October 2016

Author Corrected: $24^{\text {th }}$ October 2016

Accepted for Publication $5^{\text {th }}$ November 2016 


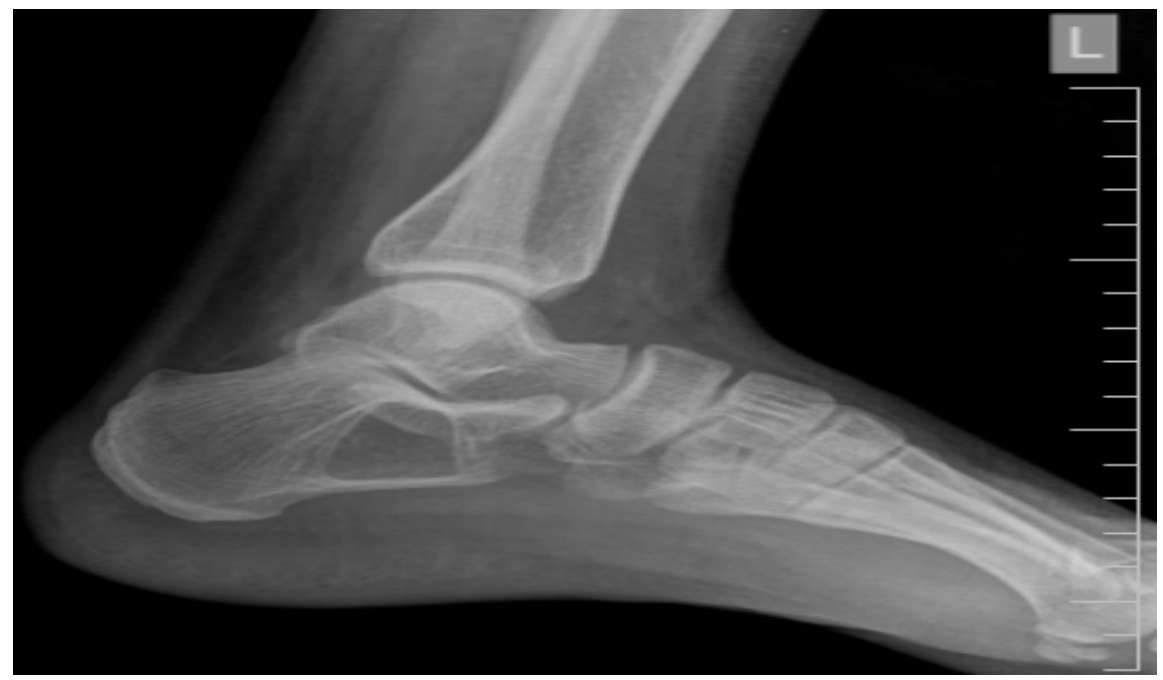

Figure-1 - Xray Lateral view

(A)

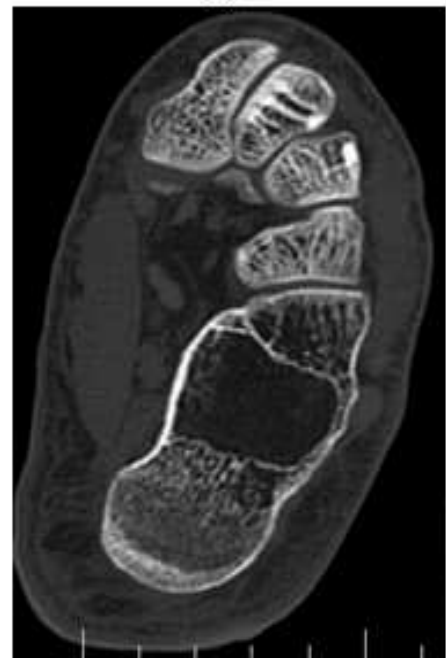

(B)

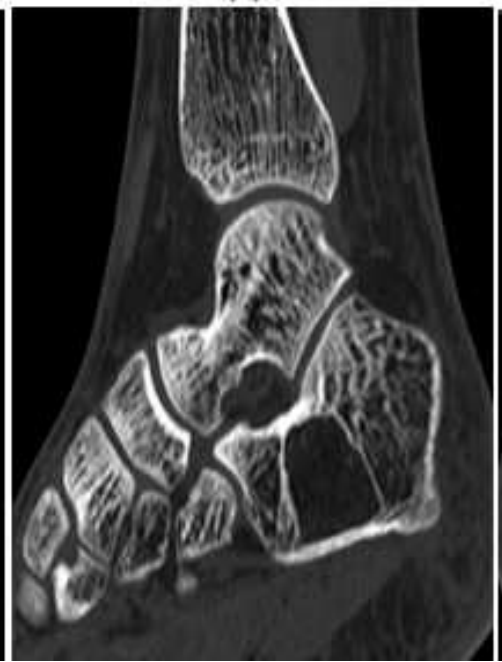

(C)

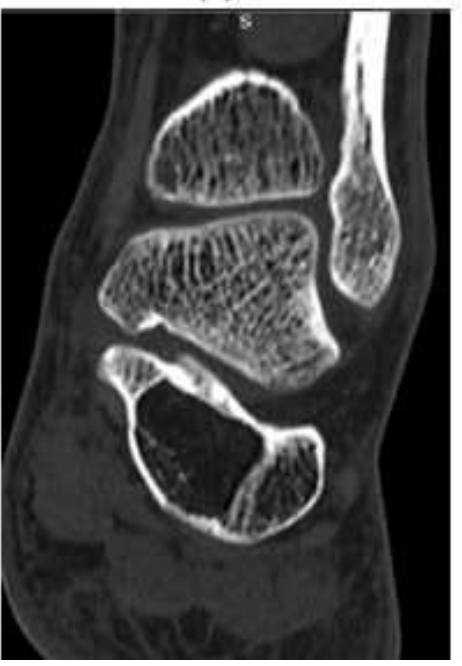

l)

(A)

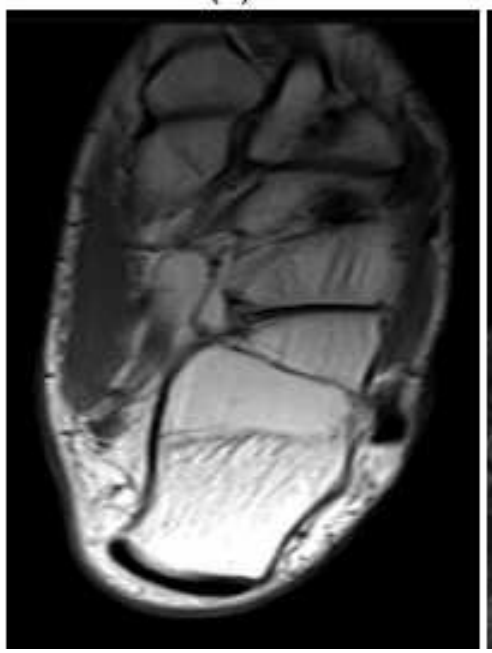

(B)
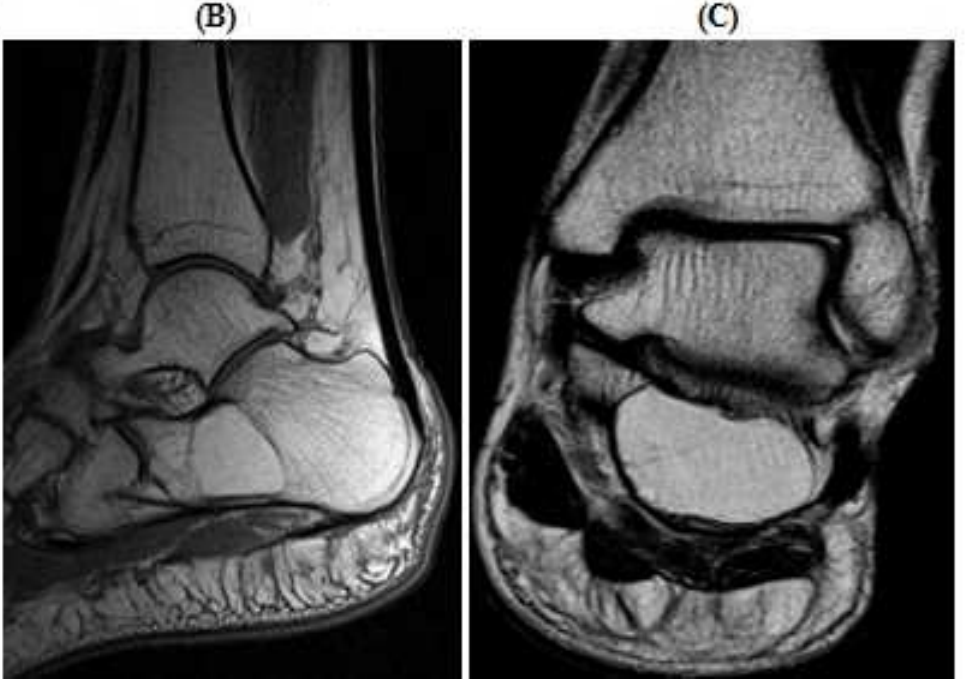

Figure-3- MRI (A- Axial T1, B- Sagittal T1, C-Coronal T2)- 
(A)

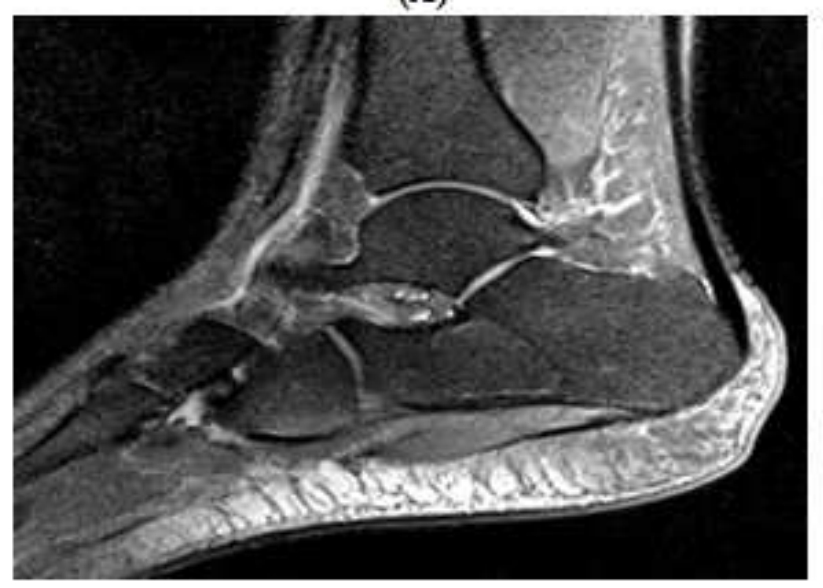

(B)

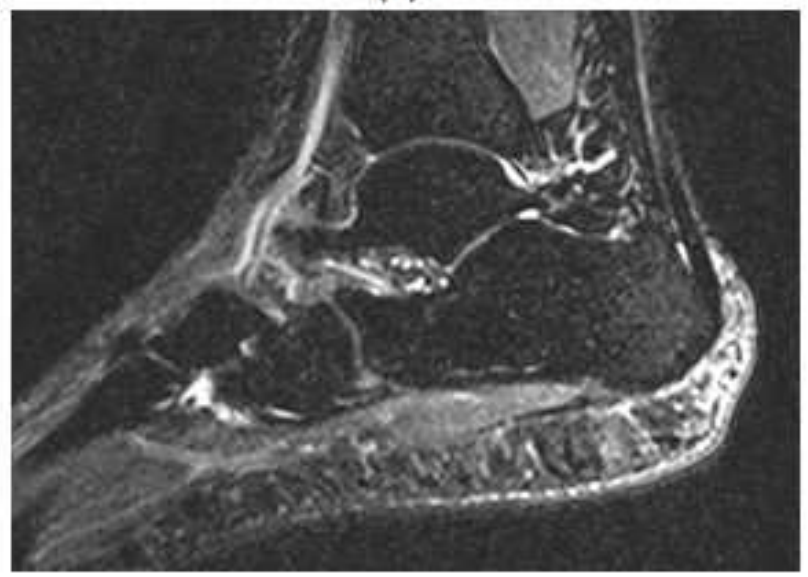

Figure-4- (A- Sagittal PDFS, B- Sagittal STIR)

\section{Discussion}

Calcaneal intraosseous lipomas usually present with bone pain from chronic expansion, or with acute symptoms related to pathologic fracture [1,2]. Differential diagnosis includes bone infarct, aneursymal bone cyst, chondromyxoid fibroma, osteoblastoma and giant cell tumor. Presence of fat signal intensity on T1weighted MR images give $100 \%$ sensitivity and specificity in the diagnosis of calcaneal intraosseous lipoma. Bone infarcts are source of diagnostic confusion, as it contains fat and often have a low signal intensity rim while calcaneal intraosseous lipoma is an expansile lesion that remodels cancellous and cortical bone, which is not a feature of bone infarction [2]. Intraosseous lipoma is often confused histologically or radiologically with fibrous dysplasia, enchondroma, osteoblastoma, chondrosarcoma, bone cyst, and bone infarct $[2,3,5,6]$. The lesion may appear as purely lytic with ill-defined margins, mimicking osteomyelitis, metastasis, or eosinophilic granuloma [7]. Although the diagnosis of intraosseous lipoma may be difficult on plain radiographs, either CT or MRI is useful in detection of fat within the lesion, for a more accurate diagnosis. However, in presence of heavy calcification and ossification within the tumor (Milgram's stage 3 lesions) difficulty may arise to diagnose these lesions on CT and MRI because most of the normal fat within the lesion is replaced with dystrophic changes [8]. CT and MRI can show the extent of the lesion, cortical involvement and soft tissue extension. The majority of intraosseous lipomas occur in the calcaneus and the metaphysis of long bones (femoral neck) [4,8,9]. According to the site of origin, osseous lipomas can be intraosseous (within the bone) and juxtacortical (on its surface). Intraosseous lipomas can be intramedullary (central) and intracortical. Surface osseous lipomas can be subperiosteal and parosteal.

A three stage classification for intraosseous lipoma was outlined by Milgram [2]. Stage I- lesions consist of viable enlarged fat cells organized into lobules which resemble mature adipose tissue. These adipocytes replace the normal bone marrow and encase the preexisting trabeculae. Stage II- lesions consist of viable lipocytes but contain areas of partial fat necrosis associated with calcification, ossification and reactive bone formation. Foci of fat necrosis contain foamy macrophages with fibrosis. Stage II and III lesions show more resorption of trabeculae than stage I lesions. Stage III lesions are heterogeneous lesions fat containing lesions with multiple areas of necrosis, cystic transformation, calcification or ossification and wall sclerosis. MR Appearance of intraosseous lipoma will vary according to stage $[2,10]$. In stage I lipoma, the lesion appears hyperintense (iso-intense to subcutaneous fat) on $\mathrm{T} 1$ and $\mathrm{T} 2 \mathrm{WI}$ and nullified on fat suppression. A thin rim of dark signal is seen due to reactive sclerosis. In stage II lipoma, viable lipocytes appear bright on $\mathrm{T} 1$ and $\mathrm{T} 2 \mathrm{WI}$ and nullified on fat suppression, calcification appear dark on T1WI and T2WI. In stage III lipoma, areas of fat necrosis will have a variable appearance on T1WI, bright on T2WI.

Central calcification and thick sclerotic rim will appear dark on T1WI and T2WI. No enhancement is noted in contrast study. On CT, the fat density lesion will show low attenuation value with the CT value of -40 to -110 HU. Calcific areas will appear hyperdense with calcific density [10]. 


\section{Conclusion}

The radiological appearance of intraosseous lipoma depends on the histologic composition of the lesion. Intraosseous lipoma can contain varying amounts of bone, fat, fibrous tissue, and cystic degeneration, resulting in a range of radiographic manifestations. The detection of a predominant fatty component in a lesion confirms its benign character and no further diagnostic work-up is required. MR imaging allows it to be discriminated from lesions of similar appearance and location, such as the identification of necrosis, fat, hemorrhage and characteristic internal calcification.

\section{Funding: Nil, Conflict of interest: None. Permission of IRB: Yes}

\section{References}

1. Murphey MD, Carroll JF, Flemming DJ, Pope TL, Gannon FH, Kransdorf MJ. From the archives of the AFIP: benign musculoskeletal lipomatous lesions. Radiographics. 2004 Sep-Oct;24(5):1433-66.

2. Milgram JW. Intraosseous lipomas: radiologic and pathologic manifestations. Radiology. 1988 Apr; 167 (1):155-60.

3. Chow LT, Lee KC. Intraosseous lipoma. A clinicopathologic study of nine cases. Am J Surg Pathol. 1992 Apr;16(4):401-10.

4. Campbell RS, Grainger AJ, Mangham DC, Beggs I, Teh J, Davies AM. Intraosseous lipoma: report of 35 new cases and a review of the literature. Skeletal Radiol. 2003 Apr;32(4):209-22. Epub 2003 Mar 12.

5. Williams CE, Close PJ, Meaney J, Ritchie D, Cogley D, Carty AT. Intraosseous lipomas. Clin Radiol. 1993 May;47(5):348-50.

6. Barcelo M, Pathria MN, Abdul-Karim FW. Intraosseous lipoma. A clinicopathologic study of four cases.Arch Pathol Lab Med. 1992 Sep;116(9):947-50.

7. Jebson PJ, Schock EJ, Biermann JS. Intraosseous lipoma of the proximal radius with extraosseous extension and a secondary posterior interosseous nerve palsy. Am J Orthop (Belle Mead NJ). 2002 Jul;31 (7):413-6.

8. Goto T, Kojima T, Iijima T, Yokokura S, Motoi T, Kawano H, Yamamoto A, Matsuda K. Intraosseous lipoma: a clinical study of 12 patients. J Orthop Sci. 2002; 7(2):274-80.

9. Hirata M, Kusuzaki K, Hirasawa Y. Eleven cases of intraosseous lipoma of the calcaneus. Anticancer Res. 2001 Nov-Dec;21(6A):4099-103.

10. Palczewski P, Swiątkowski J, Gołębiowski M, Błasińska-Przerwa K. Intraosseous lipomas: A report of six cases and a review of literature. Pol J Radiol. 2011 Oct;76(4):52-9.

\section{How to cite this article?}

Khujat R, Khaladkar S.M, Kharat A, Raj R, Doshi F, Gandage S.G. Intraosseous lipoma of the calcaneum.Int J Med Res Rev 2016;4(11):1978-1981.doi:10.17511/ijmrr. 2016.i11.13. 